\title{
Residential exposure to air pollution and access to neighborhood greenspace in relation to hair cortisol concentrations during the second and third trimester of pregnancy
}

Veerle Josefa Verheyen ${ }^{1,2^{*}}$ (D, Sylvie Remy ${ }^{1}$, Nathalie Lambrechts ${ }^{1}$, Eva Govarts ${ }^{1}$, Ann Colles $^{1}$, Lien Poelmans ${ }^{1}$, Els Verachtert ${ }^{1}$, Wouter Lefebvre ${ }^{1}$, Pieter Monsieurs' ${ }^{1}$, Charlotte Vanpoucke ${ }^{3}$, Flemming Nielsen ${ }^{4}$, Lena Van den Eeden ${ }^{5,6}$, Yves Jacquemyn $n^{5,7,8}$ and Greet Schoeters ${ }^{1,2,4}$

\begin{abstract}
Background: Exposure to air pollution during pregnancy has been associated with adverse pregnancy outcomes in studies worldwide, other studies have described beneficial effects of residential greenspace on pregnancy outcomes. The biological mechanisms that underlie these associations are incompletely understood. A biological stress response, which implies release of cortisol, may underlie associations of air pollution exposure and access to neighborhood greenspaces with health.

Methods: We explored residential exposure to air pollution and residential access to neighborhood greenspaces in relation to hair cortisol concentrations of participants in a prospective pregnancy cohort study in Flanders, Belgium. Hair samples were collected at the end of the second pregnancy trimester $(n=133)$ and shortly after delivery $(n=$ 81). Cortisol concentrations were measured in 3-cm scalp-near hair sections, to reflect second and third pregnancy trimester cortisol secretion. We estimated long-term (3 months before sampling) residential exposure to fine particulate matter $\left(\mathrm{PM}_{2.5}\right)$, nitrogen dioxide $\left(\mathrm{NO}_{2}\right)$ and black carbon $(\mathrm{BC})$, assessed residential distance to major roads and residential access to neighborhood greenspaces (NHGS). Associations between residential exposures and hair cortisol concentrations were studied using linear regression models while adjusting for season of sampling.

\footnotetext{
* Correspondence: veerle.verheyen@vito.be

${ }^{1}$ Flemish Institute for Technological Research (VITO), Mol, Belgium

${ }^{2}$ Department of Biomedical Sciences, University of Antwerp, Antwerp, Belgium

Full list of author information is available at the end of the article
}

(c) The Author(s). 2021 Open Access This article is licensed under a Creative Commons Attribution 4.0 International License, which permits use, sharing, adaptation, distribution and reproduction in any medium or format, as long as you give appropriate credit to the original author(s) and the source, provide a link to the Creative Commons licence, and indicate if changes were made. The images or other third party material in this article are included in the article's Creative Commons licence, unless indicated otherwise in a credit line to the material. If material is not included in the article's Creative Commons licence and your intended use is not permitted by statutory regulation or exceeds the permitted use, you will need to obtain permission directly from the copyright holder. To view a copy of this licence, visit http://creativecommons.org/licenses/by/4.0/. The Creative Commons Public Domain Dedication waiver (http://creativecommons.org/publicdomain/zero/1.0/) applies to the data made available in this article, unless otherwise stated in a credit line to the data. 


\begin{abstract}
(Continued from previous page)
Results: Three-month mean residential $\mathrm{NO}_{2}$ and $\mathrm{BC}$ concentrations were positively associated with third pregnancy trimester hair cortisol concentrations ( $p=0.008$ and $p=0.017$ ). Access to a large NHGS (10 ha or more within 800 $\mathrm{m}$ from residence) was negatively associated with third trimester hair cortisol concentrations $(p=0.019)$. Access to a large NHGS significantly moderated the association between residential proximity to major roads and second trimester hair cortisol concentrations ( $p=0.021$ ). Residential distance to major roads was negatively associated with second trimester hair cortisol concentrations of participants without access to a large NHGS $(p=0.003)$. The association was not significant for participants with access to a large NHGS. The moderation tended towards significance in the third pregnancy trimester $(p<0.10)$.
\end{abstract}

Conclusions: Our findings suggest a positive association between long-term residential exposure to air pollution and biological stress during pregnancy, residential access to neighborhood greenspaces may moderate the association. Further research is needed to confirm our results.

Trial registration: The IPANEMA study is registered under number NCT02592005 at clinicaltrials.gov.

Keywords: Air pollution, Proximity to major roads, Neighborhood greenspace, Pregnancy, Longer-term biological stress, Hair cortisol concentrations

\section{Background}

In the past decade, epidemiological studies throughout the world have linked maternal exposure to road traffic and air pollution to adverse pregnancy outcomes such as low birth weight, preterm birth and intrauterine growth restriction [1-3]. These adverse birth outcomes not only increase perinatal morbidity and mortality, but also increase susceptibility to obesity, diabetes and cardiovascular diseases later in life $[4,5]$. Exposure to air pollution may also affect maternal health, ambient air pollution has been linked to hypertensive pregnancy disorders (gestational hypertension, pre-eclampsia) and gestational diabetes mellitus [6-8]. Both conditions amplify young women's risk of developing cardiovascular diseases later in life [9]. The adverse impact of maternal exposure to air pollution on birth outcomes is of major public health importance, considering the ubiquitous nature of air pollution in urban settings [10]. The biological pathways that underlie associations between maternal exposure to air pollution and adverse pregnancy outcomes however, remain incompletely understood. Recent experimental animal research has shown that a neuroendocrine stress response is among the early biological responses triggered by exposure to fine particulate matter with an aerodynamic diameter $\leq 2.5 \mu \mathrm{m}\left(\mathrm{PM}_{2.5}\right)$ and exposure to nitrogen dioxide $\left(\mathrm{NO}_{2}\right)$ [11]. The biological stress response includes activation of the hypothalamic-pituitaryadrenal (HPA) axis and release of glucocorticoid stress hormones, with the glucocorticoid cortisol as its main downstream effector in humans [12]. The relevance of these experimental observations to humans has been confirmed in a few recent studies [13, 14]. To date, most human studies have assessed short-term variations in cortisol levels in relation to air pollution exposure, using blood and saliva as a matrix. Longer-term cortisol concentrations are difficult to evaluate using blood and saliva, due to circadian variations in cortisol secretion and the need for multiple sampling [15]. Repeated sampling increases discomfort for study participants. Hair however, is a suitable matrix for the assessment of longer-term cortisol concentrations [16]. As cortisol is incorporated into growing hair, hair cortisol concentrations (HCC) retrospectively reflect cortisol secretion over a period of several months [17]. The validity of HCC as an index of long-term systemic cortisol concentrations has been demonstrated in direct and indirect validation studies [18]. Strong positive associations between HCC and mean salivary cortisol levels, obtained through repeated sampling, were first established in rhesus macaques and later confirmed in human studies, including a study in pregnant women $[18,19]$. In experimental animal studies, repeated stimulation of cortisol secretion by administration of HPA-axis hormones (adrenocorticotropic hormone, corticotropinreleasing hormone), was associated with an increased accumulation of cortisol in hair [20]. Research has also associated HCC with conditions that are known to be related to altered adrenocortical function, such as Cushing's syndrome, Addison's disease and cardiovascular diseases [21]. Importantly, chronic activation of the maternal HPA axis during pregnancy has been associated with gestational hypertensive disorders, intrauterine growth restriction and developmental programming of disease susceptibility $[22,23]$. With regard to birth outcomes, a significant negative association between maternal HCC in the 2nd pregnancy trimester and gestational age at delivery has been reported [24].

Interestingly, a growing body of research suggests a beneficial relationship between residential access to greenspaces (community gardens, urban parks, forests) and pregnancy outcomes for both mothers and babies [25]. Physiological stress recovery has been suggested as 
a potential biological pathway, linking residential access to neighborhood greenspace to health [26, 27]. A relationship between the use of urban neighborhood greenspace and decreased hair cortisol concentrations has previously been demonstrated in an adult population in Berlin, Germany [28]. According to the World Bank, $55 \%$ of the world's population lived in cities in 2019, this trend is expected to continue in the coming decades [29]. Given the ubiquitous nature of air pollution in urban settings, residential access to neighborhood greenspaces may play an important role in protecting and promoting urban health [30]. The adverse effects of air pollution may, to some degree, be moderated by the beneficial effects of residential access to greenspace [31].

To our knowledge, no research is available on residential air pollution exposure or access to neighborhood greenspace in relation to longer-term biological stress during pregnancy. Accordingly, we aimed to explore 1) associations of residential exposure to air pollution and proximity to major roads with maternal hair cortisol concentrations during the second and third trimester of pregnancy and 2) associations of residential access to neighborhood greenspace with maternal hair cortisol concentrations during the second and third trimester of pregnancy. In addition, we aimed to explore whether residential access to a neighborhood greenspace moderated associations of residential exposure to air pollution and proximity to major roads with maternal biological stress.

\section{Methods}

\section{Study population and design}

This study was conducted in the framework of IPAN EMA (Impact of Particulate Matter on Mothers and Babies in Antwerp), a prospective pregnancy cohort study of the Antwerp University Hospital (UZA) in collaboration with the Flemish Institute for Technological Research (VITO) and the University of Antwerp (UA). Pregnant women were recruited between April 2015 and January 2018 at the UZA prenatal clinic by a midwife or obstetrician at a gestational age of 12 to 14 weeks. The inclusion criteria were: a singleton pregnancy; the ability to fill out extensive Dutch questionnaires; delivery planned in the Antwerp University Hospital. All participating mothers gave written informed consent. The study protocol was approved by the ethical committee of the University of Antwerp (14/40/411) and registered under number NCT02592005 at clinicaltrials.gov. Health-related information on mothers and babies was extracted from the hospital records and questionnaires that participants completed at enrolment, during pregnancy and after delivery. These questionnaires provided detailed information on participants' socio-demographic and lifestyle characteristics. A detailed protocol of the IPANEMA study can be found elsewhere [32].

\section{Residential exposure assessment}

Assessment of all residential exposure variables was based on the participants' geocoded home address. Geographical Information System (GIS) analyses were carried out using ESRI ArcGIS software version 10.4 (Environmental Systems Research Institute, Redlands, California, USA). The residential degree of urbanization was assessed according to the Eurostat definition that classifies local administrative units as cities, towns, suburbs or rural areas based on a combination of geographical contiguity and population density, applied to $1 \mathrm{~km}^{2}$ population grid cells [33]. We assessed residential exposure to fine particulate matter $\left(\mathrm{PM}_{2.5}\right)$, nitrogen dioxide $\left(\mathrm{NO}_{2}\right)$ and black carbon (BC), primary constituents of traffic-related air pollution. Residential exposure to $\mathrm{PM}_{2.5}, \mathrm{NO}_{2}$ and $\mathrm{BC}$ was modelled using a spatial temporal interpolation method. In Flanders, atmospheric pollutants are continuously measured by a network of automatic monitoring stations by the Flemish Environment Agency. The Belgian Interregional Environment Agency (IRCEL, Intergewestelijke Cel voor het Leefmilieu) uses these measurements together with information on land cover to interpolate the air pollutant concentrations on a $4 \times 4 \mathrm{~km}^{2}$ resolution [34]. These background results are combined with a bi-gaussian dispersion model based on emissions from point sources and line sources, the Immission Frequency Distribution Model (IFDM). The combined RIO-IFDM model chain produces daily averaged pollutant concentrations in Belgium on a high resolution receptor grid [35]. We calculated mean air pollutant concentrations at the residential address over a 3-month period before sampling, similar to the period of cortisol accumulation in the hair samples, and over a 1-year period before sampling. Residential proximity to major roads is often used as a surrogate measure of long-term exposure to traffic-related air pollution [36]. We calculated the straight-line distance from each residence to the nearest major road. Major roads included international motorways (E-roads) and the network of large national and local roads of Belgium (Nroads).

Residential access to a neighborhood greenspace was based on the 2016 version of the land-use map of Flanders, which maps land cover types, i.e. natural vegetated land cover and urban greenery, in $10 \times 10 \mathrm{~m}^{2}$ raster cells [37]. Green cells were clustered to assess the area and public accessibility of greenspace in the maternal residential surroundings. Access to a small neighborhood greenspace (NHGS) was defined as access to at least 0.2 ha (ha) of greenspace within a travel distance of $400 \mathrm{~m}$ (m) from residence, access to a large greenspace was 
defined as access to at least 10 ha of greenspace within a travel distance of $800 \mathrm{~m}$ from residence. In the large greenspace typology, small water bodies are included when surrounded by $>50 \%$ greenspace, agricultural land is included when surrounded by $>30 \%$ greenspace. More technical background information on the green typology indicators can be found elsewhere [38].

\section{Hair sample collection and cortisol measurement}

At the end of second trimester of pregnancy in-hospital consultation and shortly after delivery, a strand of hair of at least $2 \mathrm{~mm}$ thick was bound together with a cotton thread and cut close to the scalp from the posterior vertex region of the head. This area of the scalp exhibits the lowest intra-individual variability in HCC [39]. Hair samples were stored in paper envelopes at room temperature until analysis. When protected from ultraviolet light, cortisol concentrations in hair samples remain stable at room temperature for several years [40]. Cortisol concentrations were determined from the $3 \mathrm{~cm}$ of hair closest to the scalp. Based on an average hair growth of $1 \mathrm{~cm}$ per month, this length represents cortisol secretion in a 3-month period, a trimester, prior to sampling [41]. The samples taken in this study are therefore indicative of hair cortisol concentrations during the second and third trimester of pregnancy. There is a wide consensus that the first 5-6 cm of hair nearest to a person's scalp can reliably reflect HPA activity [42]. Analysis was performed at the Institute of Public Health, Department of Environmental Medicine of the University of Southern Denmark (SDU), using liquid chromatography and tandem mass spectrometry (LC-MS/MS) as described by Chen et al. [43], after minor modifications. Hair samples were washed with methanol and dried at room temperature. The $3 \mathrm{~cm}$ of hair closest to the scalp was cut into segments of $2-3 \mathrm{~mm}$. A typical amount of hair weighed $20-30 \mathrm{mg}$. Aliquots of $100 \mu \mathrm{L} 20 \mathrm{ng} / \mathrm{mL}$ isotope labeled cortisol (cortisol- $\mathrm{D}_{4}$ ) were added as internal standard, together with $0.9 \mathrm{~mL}$ methanol. Samples were incubated in the dark at $25^{\circ} \mathrm{C}$ while whirl mixed at $2000 \mathrm{rpm}$ for 5 days and subsequently centrifuged at $3000 \mathrm{~g}$ for $5 \mathrm{~min}$. Twenty microliter of the supernatant was injected onto a High-Performance Liquid Chromatography (HPLC) column. HPLC was performed using an Accella 1250 pump (Thermo Scientific, San Jose, CA) and a PAL autosampler (CTC analytics, Zwingen, Switzerland). The analytical column was a Kinetex C18 column, $100 \times$ $4.6 \mathrm{~mm}(2.6 \mu \mathrm{m})$ equipped with a $2 \times 4 \mathrm{~mm} \mathrm{C18} \mathrm{Security-}$ Guard column (Phenomenex, Torrance, CA). Isocratic elution was performed with a mobile phase system consisting of methanol and $0.1 \mathrm{M}$ formic acid (80:20) at a flow rate of $400 \mu \mathrm{L} / \mathrm{min}$ for $6 \mathrm{~min}$. After the peaks were eluted, a wash procedure was performed before the next samples was injected onto the column. The triple quadrupole mass spectrometer utilized was a TSQ Vantage (Thermo Scientific, San Jose, CA). The calibration curve and calculation of the sample concentration were based on the area ratio of the analyte/isotope labeled internal standard. Quality control samples were included in each series of samples. The limit of quantification (LOQ) for cortisol was $1.0 \mathrm{pg} / \mathrm{mg}$ hair. The intra-day repeatability coefficient of variation was $8.7 \%$ and the inter-day reproducibility coefficient of variation was $9.5 \%$.

\section{Potential covariates}

The selection of potential covariates was based on existing literature [18, 44-48]. A meta-analysis of HCC research identified age and hair washing frequency as potential covariates of HCC [18]. Other studies have identified household socioeconomic status (SES), anthropometry, chronic diseases and the local use of glucocorticoids as potential covariates of HCC [44, 46, 47]. Studies on determinants of HCC in pregnant women suggested pre-pregnancy BMI, parity, season of sampling and gestational week at sampling as potential covariates of HCC during pregnancy $[45,48]$. In this study, we had information on maternal age, parity, maternal socioeconomic status (SES) defined as the highest educational attainment of the mother and categorized as low/intermediate/high, pre-existing chronic diseases (diabetes, asthma, cardiovascular disease), pre-pregnancy body mass index (BMI), gestational week at sampling, season of sampling, smoking and alcohol consumption before pregnancy, systemic use of glucocorticoids and daily hair washing. We assessed maternal ethnic background as European/non-European country of birth since hair growth rate may be influenced by ethnicity [49]. We additionally assessed variables that may have a link with both residential environment and biological stress, i.e. neighborhood SES and residential exposure to noise. A systematic review in the World Health Organization (WHO) European Region showed that lower neighborhood SES is usually linked with higher levels of air pollutants [50]. Independent from higher levels of exposure, deprived mothers may have a higher vulnerability, leading to more pronounced adverse health effects of a given environmental exposure [51]. The Area Deprivation Index (ADI) is a yearly calculated indicator for neighborhood SES on a sub-municipality level in Flanders [52]. Deprivation is recorded by the Flemish Child and Family Government Agency (www.kindengezin.be). Selection criteria for deprivation are the family's monthly income, the parents' educational attainment, the children's development, the parents' employment situation, housing and health. If a family fulfils three or more criteria, it is considered to be underprivileged [53]. The index of year X (\%), i.e. 2017, considers all children born in year X, X-1 and $\mathrm{X}-2$ that live in deprived households in a given area 
in Flanders, divided by the total number of children born in the area during the same period. The ADI of the participants' neighborhood was subsequently categorized into tertiles representing low, intermediate and high area deprivation across the range of ADI among all participants.

Residential proximity to major roads may also lead to elevated noise levels [54]. Residential noise exposure levels were assessed using the Flemish strategic noise map of 2016, which includes major road infrastructure as defined in the EU-guideline 2002/49/EG [55]. The strategic noise map expresses noise levels in $L_{d e n}$, the average sound level over a $24 \mathrm{~h}$ period with a penalty of $5 \mathrm{~dB}$ added for evening hours and a penalty of $10 \mathrm{~dB}$ added for nighttime hours [56]. The WHO guideline for average noise exposure produced by road traffic is set at $53 \mathrm{~dB}(\mathrm{~dB}) \mathrm{L}_{\mathrm{den}}$, road traffic noise above this level has been associated with adverse health effects, including adverse birth outcomes [57]. Noise exposure was therefore evaluated binary as exposure to a noise level $\geq 53 \mathrm{~dB}$ $\mathrm{L}_{\mathrm{den}}$.

\section{Statistical analysis}

Statistical analysis was performed using SPSS Statistics (version 25; IBM, Armonk, NY, USA) and R (version 2018; R Foundation for Statistical Computing, Vienna, Austria). Descriptive statistics provide an overview of study population characteristics, residential exposure characteristics and geometric mean HCC concentration with 95\% confidence interval. Air pollution variables were logarithmically transformed (ln-scale) because of skewed distributions, distance to major roads was logarithmically transformed to reflect the non-linear distance decay of traffic-related exposure to air pollutants [58].

Spearman rank correlations between residential exposures variables were assessed, since correlations of 0.9 or higher between exposure variables indicate strongly connected exposures that cannot be disentangled [59]. The outcome variable $\mathrm{HCC}$ was logarithmically transformed to obtain a normal distribution. For HCC below the LOQ of $1 \mathrm{pg} / \mathrm{mg}$ hair, a random imputation from a lognormal probability distribution was performed where the mean was allowed to depend on observed values for hair cortisone concentrations that were measured simultaneously with cortisol, since both glucocorticoids were highly correlated ( $p<0.01$, Pearson's $r=0.711$ for 2nd trimester cortisol and cortisone, $p<0.01$, Pearson's $r=$ 0.758 for 3 rd trimester cortisol and cortisone). Linear regression models were used to analyze associations between 3-month mean air pollutant concentrations $\left(\mathrm{PM}_{2.5}, \mathrm{NO}_{2}, \mathrm{BC}\right)$, distance to major roads and access to neighborhood greenspace as a predictor and 2nd and 3rd trimester HCC as an outcome. Given the limited number of study participants, we decided not to adjust for a set of a priori selected covariates. We assessed the significance of the aforementioned potential covariates in relation to $\mathrm{HCC}$ in this cohort by performing a univariate analysis of variance (ANOVA). We then specified two linear regression models. Model I was unadjusted, model II was adjusted for season of sampling, based on its significance as a covariate of HCC $(p<0.05)$ in the ANOVA. All assumptions of linear regression were checked. To quantify the associations of continuous exposure variables with $\mathrm{HCC}$, the effect estimates with 95\% confidence intervals $(95 \% \mathrm{CI})$ are presented as the factor change in $\mathrm{HCC}$ for a factor increase in exposure from the 25th to the 75th percentile. The factor increase in exposure is calculated as the ratio of the 75th to the 25th percentile ( $\mathrm{p} 75 / \mathrm{p} 25)$ of the exposure variable. To quantify the associations of access to neighborhood greenspace with HCC, the effect estimates ( $\beta$ ) with 95\% $\mathrm{CI}$ are presented for having access to neighborhood greenspace, compared to having no access to neighborhood greenspace.

Effect modification by access the neighborhood greenspace was assessed by adding the interaction term of exposure to air pollution or distance to major roads and access to neighborhood greenspace into the regression model. The significance of the interactions is reported ( $p$-interaction). For significant interactions, the effect estimates $(\beta)$ with their $95 \% \mathrm{CI}$ are reported for participants with access to neighborhood greenspace and for participants without access to neighborhood greenspace. The level of significance for associations and interactions was set at $p<0.05$.

We conducted several sensitivity analyses to evaluate our results. We tested 1-year mean air pollutant concentrations in relation to 2nd and 3rd trimester HCC to confirm the robustness of 3-month mean results. We additionally adjusted our models for frequency of hair washing, a factor that may influence $\mathrm{HCC}$, independently of biological stress. We additionally adjusted the models for maternal age, pre-pregnancy BMI $\geq 25$ (overweight and obese), educational attainment and ADI > the study mean of $16.4 \%$, to evaluate potential residual confounding. As a final sensitivity analysis, associations between residential exposures and HCC were investigated while excluding participants that reported a nonEuropean country of birth.

\section{Results}

Hair samples for cortisol analysis were provided by 152 participants. Characteristics of the study population are described in Table 1 . We excluded 3 participants due to inexplicable high $\mathrm{HCC}$ values ( $>3$ times the interquartile range above the third quartile). As a result, 149 pregnant women were included in this study, of which 133 women donated a sample at the end of the 2nd trimester 
Table 1 Basic characteristics of the study participants

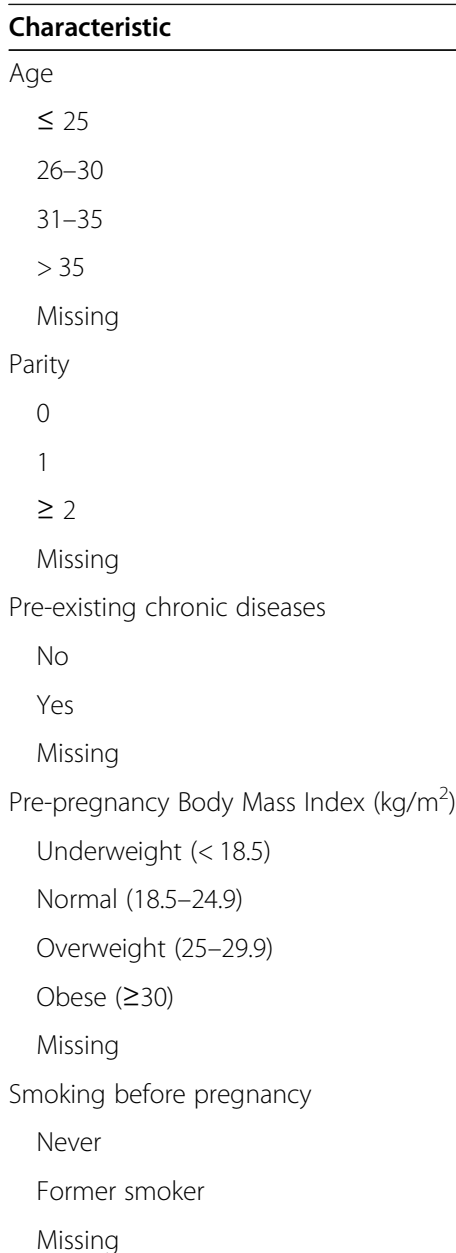

Alcohol consumption before pregnancy

$$
\begin{aligned}
& \text { No } \\
& \text { Yes } \\
& \text { Missing }
\end{aligned}
$$

Ethnic background

European
Non-European
Missing
ducational attainment
Low (Basic level)
Intermediate (Secondary school)
High (Higher education)
Missing

Pre-pregnancy employment

$$
\begin{aligned}
& \text { No } \\
& \text { Yes }
\end{aligned}
$$$$
\text { Missing }
$$$$
\text { Daily hair washing }
$$$$
\text { No }
$$

$n(\%)$

$17(11.4)$
$71(47.7)$
$44(29.5)$
$17(11.4)$
0
$91(61.1)$
$43(28.9)$
$15(10)$
0

135 (90.6)

$12(8.1)$

2 (1.3)

8 (5.4)

$84(56.4)$

$20(13.4)$

$12(8.1)$

$25(16.7)$

$94(63.1)$

$21(14.1)$

$34(22.8)$

$16(10.7)$

99 (66.4)

$34(22.8)$

$112(75.2)$

$4(2.7)$

$33(21.1)$

$15(10.1)$

$15(10.1)$

$85(57.0)$

$34(22.8)$

$7(4.7)$

$107(71.8)$

$35(23.5)$

$97(65.1)$
Table 1 Basic characteristics of the study participants (Continued)

\begin{tabular}{ll}
\hline Characteristic & $\boldsymbol{n}(\%)$ \\
\hline Yes & $18(12.1)$ \\
Missing & $34(22.8)$ \\
Season of 2nd trimester sampling $(n=133)$ & \\
Autumn & $28(21.2)$ \\
Winter & $23(17.3)$ \\
Spring & $38(28.6)$ \\
Summer & $44(33.1)$ \\
Missing & 0 \\
Season of 3rd trimester sampling $(n=81)$ & \\
Autumn & $23(28.4)$ \\
Winter & $21(25.9)$ \\
Spring & $12(14.8)$ \\
Summer & $25(30.9)$ \\
Missing & 0
\end{tabular}

Note: pre-existing chronic diseases include diabetes, asthma, cardiovascular diseases

(week $26 \pm 1.6$ ) and 81 women shortly after delivery (week $39 \pm 1.6$ ), 65 women donated a sample twice. Almost half of the 149 mothers (48\%) was aged between 26 and 30 years, $61 \%$ of participants were primigravid. Most of the study participants were of European origin (75, 21\% data missing), enjoyed higher education (57, $23 \%$ data missing) and were employed prior to their pregnancy (72, 23.5\% data missing).

Residential characteristics are described in Table 2. Study participants lived in cities (38\%), towns and suburbs $(62 \%)$ in Flanders, none of the participants lived in a rural area. The mean ADI of our study population was 16.4\% (95\% CI: 14.6, 18.1) whereas the mean 2017 ADI for the study region Antwerp was 17.6\% (Statistics Flanders, n.d.). We tested the significance of the association between ADI as an area-level SES indicator and maternal educational attainment as a personal SESindicator. We did not observe a significant association between neighborhood SES and personal SES (Spearman rank $r=-0.074, p=0.404)$. A small neighborhood greenspace was accessible for $94 \%$ of participants, $76 \%$ had residential access to a large greenspace. Threemonth geometric mean $\mathrm{PM}_{2.5}$ was 11.61 (95\% CI: 11.06, 12.21) $\mu \mathrm{g} / \mathrm{m}^{3}$ and 11.55 (95\% CI: $\left.10.95,12.18\right) \mu \mathrm{g} / \mathrm{m}^{3}$ for 2nd trimester and 3rd trimester sampling respectively. Geometric mean $\mathrm{NO}_{2}$ concentrations 3 months before sampling was 23.03 (95\% CI: 21.67, 24.47) $\mu \mathrm{g} / \mathrm{m}^{3}$ for the 2nd trimester and 23.19 (95\% CI: 21.5, 24.98) $\mu \mathrm{g} / \mathrm{m}^{3}$ for the 3rd trimester, 3-month geometric mean BC concentration $1.13(95 \%$ CI: $1.05,1.21) \mu \mathrm{g} / \mathrm{m}^{3}$ for the 2nd trimester and 1.17 (95\% CI: $1.07,1.28) \mu \mathrm{g} / \mathrm{m}^{3}$ for the 3rd trimester. Noise exposure was covered by the Flemish 
Table 2 Residential characteristics of the study participants

\begin{tabular}{|c|c|}
\hline \multicolumn{2}{|l|}{ Variable } \\
\hline Categorical variables $(n=149)$ & $n(\%)$ \\
\hline \multicolumn{2}{|l|}{ Neighborhood greenspace } \\
\hline \multicolumn{2}{|l|}{ Access to small neighborhood greenspace } \\
\hline No & $9(6.0)$ \\
\hline Yes & $140(94.0)$ \\
\hline \multicolumn{2}{|l|}{ Access to large neighborhood greenspace } \\
\hline No & $36(24.2)$ \\
\hline Yes & $113(75.8)$ \\
\hline \multicolumn{2}{|l|}{ Eurostat urbanization } \\
\hline Cities & $56(37.6)$ \\
\hline Towns and suburbs & $93(62.4)$ \\
\hline Rural & 0 \\
\hline \multicolumn{2}{|l|}{ Noise levels } \\
\hline$L_{\text {den }}<53 \mathrm{~dB}$ & $97(65.1)$ \\
\hline$L_{\text {den }} \geq 53 \mathrm{~dB}$ & $47(31.5)$ \\
\hline Missing & $5(3.4)$ \\
\hline Continuous variables & $\begin{array}{l}\text { Geometric mean } \\
(95 \% \mathrm{Cl})\end{array}$ \\
\hline Distance to major roads $(\mathrm{m})(n=149)$ & $290(240,349)$ \\
\hline \multicolumn{2}{|l|}{ 2nd trimester air pollution $\left(\mu \mathrm{g} / \mathrm{m}^{3}\right)(n=133)$} \\
\hline $\mathrm{NO}_{2} 90$ days prior to sampling & $23.03(21.67,24.47)$ \\
\hline $\mathrm{NO}_{2} 1$ year prior to sampling & $24.55(23.39,25.76)$ \\
\hline $\mathrm{PM}_{2.5} 90$ days prior to sampling & $11.61(11.06,12.21)$ \\
\hline $\mathrm{PM}_{2.5} 1$ year prior to sampling & $13.09(12.81,13.37)$ \\
\hline BC 90 days prior to sampling & $1.13(1.05,1.21)$ \\
\hline BC 1 year prior to sampling & $1.29(1.24,1.36)$ \\
\hline \multicolumn{2}{|l|}{ 3rd trimester air pollution $\left(\mu \mathrm{g} / \mathrm{m}^{3}\right)(n=78)$} \\
\hline $\mathrm{NO}_{2} 90$ days prior to sampling & $23.19(21.53,24.98)$ \\
\hline $\mathrm{NO}_{2} 1$ year prior to sampling & $24.70(23.27,26.23)$ \\
\hline $\mathrm{PM}_{2.5} 90$ days prior to sampling & $11.55(10.95,12.18)$ \\
\hline $\mathrm{PM}_{2.5} 1$ year prior to sampling & $12.70(12.42,12.99)$ \\
\hline BC 90 days prior to sampling & $1.17(1.07,1.28)$ \\
\hline BC 1 year prior to sampling & $1.29(1.21,1.37)$ \\
\hline \multicolumn{2}{|l|}{ Ambient temperature ( ${ }^{\circ} \mathrm{Celsius)}$} \\
\hline 90 days prior to 2 nd trimester sampling $(n=133)$ & $10.5(9.7,11.4)$ \\
\hline 90 days prior to 3 rd trimester sampling $(n=81)$ & $12.6(11.7,13.3)$ \\
\hline Area deprivation index (\%) $(n=149)$ & $16.4(14.6,18.1)$ \\
\hline
\end{tabular}

Note: Categorical data is described as frequencies (\%), continuous data is described by geometric mean with $95 \%$ confidence interval $(95 \% \mathrm{Cl})$. All data is based on the maternal residential address. Major roads include E- or Nroads. Access to small neighborhood greenspace is defined as access to $>0.2$ ha (ha) of greenspace within a travel distance of $400 \mathrm{~m}(\mathrm{~m})$ from residence, access to large neighborhood greenspace is defined as access to $>10$ ha of greenspace within a travel distance of $800 \mathrm{~m}$ from residence. $L_{\text {den }}$ dayevening-night noise level, $\mathrm{NO}_{2}$, nitrogen dioxide; $\mathrm{PM}_{2.5}$, fine particulate matter with an aerodynamic diameter $\leq 2.5 \mu \mathrm{m} ; \mathrm{BC}$, black carbon strategic noise map for 144 participants, $31.5 \%$ of participating mothers was exposed to noise levels $\geq 53 \mathrm{~dB}$. Geometric mean 2nd trimester HCC was 3.94 (95\% CI: $3.49,4.45) \mathrm{pg} / \mathrm{mg}$ hair, geometric mean 3rd trimester HCC was 6.12 (95\% CI: 4.96, 7.56) pg/mg hair. The coefficient of variance (CV) of 2nd trim $\mathrm{HCC}$ was $51.5 \%$, CV of 3 rd trimester HCC was $51.8 \%$. Second and third trimester cortisol concentrations of participants that donated a hair sample twice were moderately correlated ( $n$ $=65, p<0.01$, Pearson's $r=0.571$ ).

Spearman rank correlations of residential exposure characteristics are presented in Table 3 (2nd trimester study population) and Table 4 (3rd trimester study population).

We observed strong positive correlations between 3month mean air pollutant concentrations ( $r$ ranged from 0.61 to 0.89 ). Distance to major roads was negatively correlated with $\mathrm{NO}_{2}$ and $\mathrm{BC}$ concentrations $(r$ ranged from -0.24 and -0.37 ), but not with $\mathrm{PM}_{2.5}$ concentrations.

Access to a neighborhood greenspace did not significantly correlate with air pollutants and distance to major roads in the 2 nd trimester. In the 3rd trimester study population, we did find weak negative correlations between access to a large neighborhood greenspace and air pollutants ( $r$ ranged from -0.28 to -0.31 ) and a weak positive association of access to a large neighborhood greenspace with distance to major road $(r=0.26)$. The ADI was weakly positively correlated with $\mathrm{NO}_{2}, \mathrm{BC}$ and noise exposure above the WHO guideline ( $r$ ranged from 0.21 to 0.46 ) and negatively correlated with distance to major roads and access to a large neighborhood greenspace ( $r$ ranged from -0.18 to -0.25 ).

In the ANOVA, season of sampling and daily hair washing were identified as significant covariates of 2nd trimester HCC, no significant covariates were identified for 3rd trimester HCC (see Table S1 for details). None of the participants reported the systemic use of glucocorticoids. Residential noise exposure above the WHO guideline $\left(\geq 53 \mathrm{~dB} \mathrm{~L}_{\mathrm{den}}\right)$ was not significantly associated with 2nd or 3rd trimester HCC ( $p=0.871, p=0.190$ respectively). Nor did we find significant associations between the ADI and 2nd or 3rd trimester $\operatorname{HCC}(p=$ $0.661, p=0.388$ resp.).

Results of the associations between air pollution exposure, access to neighborhood greenspace and maternal biological stress are presented in Table 5 . We found a significant negative association between 3 -month mean $\mathrm{PM}_{2.5}$ concentrations and 2nd trimester HCC in the unadjusted model ( $\beta=0.81$ (95\% CI: 0.70, 0.95), $p=0.009$ ), the association did not remain significant after adjustment for season of sampling ( $\beta=0.87$ (95\% CI: 0.70 , $1.08), p=0.200)$. In the 3rd trimester, 3-month mean $\mathrm{PM}_{2.5}$ concentrations were not significantly associated 
Table 3 Spearman rank correlations between residential exposures in the 2nd trimester study population $(\mathrm{n}=133)$

\begin{tabular}{|c|c|c|c|c|c|c|c|}
\hline & BC & $\mathrm{NO}_{2}$ & Distance to major road & Small greenspace & Large greenspace & Noise & ADI \\
\hline \multirow[t]{7}{*}{ PM2.5 } & $0.68^{*}$ & $0.68^{*}$ & -0.15 & -0.02 & -0.04 & 0.08 & 0.15 \\
\hline & $\mathrm{BC}$ & $0.89^{*}$ & $-0.29^{*}$ & -0.09 & -0.14 & $0.28^{*}$ & $0.38^{*}$ \\
\hline & & $\mathrm{NO}_{2}$ & $-0.37^{*}$ & -0.08 & -0.12 & $0.31^{*}$ & $0.46^{*}$ \\
\hline & & & Distance to major road & 0.01 & 0.17 & $-0.32^{*}$ & -0.20 \\
\hline & & & & Small greenspace & $0.43^{*}$ & -0.14 & -0.11 \\
\hline & & & & & Large greenspace & $-0.20^{*}$ & -0.18 \\
\hline & & & & & & Noise & 0.21 \\
\hline
\end{tabular}

"Significant correlations $(p<0.05)$

Note: Air pollutants were modelled at the maternal home address, 3-month mean concentrations were calculated. Major roads include E- or N-roads. Access to small neighborhood greenspace is defined as access to $>0.2$ ha (ha) of greenspace within a travel distance of $400 \mathrm{~m}$ ( $\mathrm{m}$ ) from residence, access to large neighborhood greenspace is defined as access to $>10$ ha of greenspace within a travel distance of $800 \mathrm{~m}$ from residence. Noise exposure is evaluated as exposure above the $\mathrm{WHO}$ health-based guideline of $53 \mathrm{~dB}$ Lden (day-evening-night noise level). $A D I$ Area deprivation index, $\mathrm{NO}_{2} \mathrm{Nitrogen}$ dioxide, $P \mathrm{M}_{2.5}$ Fine particulate matter with an aerodynamic diameter $\leq 2.5 \mu \mathrm{m}, B C$ Black carbon

with $\mathrm{HCC}$ in the unadjusted model $(\beta=1.20$ (95\%CI: $0.89,1.62), p=0.227)$, we observed a tendency towards a significant positive association after adjustment for season of sampling $(\beta=1.46$ (95\% CI: $1.01,2.11), p=$ 0.051).

We did not observe significant associations between 3month mean $\mathrm{NO}_{2}$ and $\mathrm{BC}$ concentrations and 2nd trimester HCC. We observed a significant positive association between 3-month mean $\mathrm{NO}_{2}$ concentrations and 3rd trimester HCC in the unadjusted model $(\beta=1.42$ (95\% CI: $1.07,1.88), p=0.016$ ), the association remained significant after adjustment for season of sampling ( $p=$ $0.008)$. For an increase of 3 -month mean residential $\mathrm{NO}_{2}$ concentrations with a factor $1.63\left(18.35 \mu \mathrm{g} / \mathrm{m}^{3}\right.$ (p25) to $30 \mu \mathrm{g} / \mathrm{m}^{3}$ (p75)), an increase of 3rd trimester HCC with a factor 1.53 (95\% CI: 1.12, 2.09) was estimated in the model, adjusted for season of sampling. We also observed a significant positive association between 3-month mean $\mathrm{BC}$ concentrations and 3rd trimester HCC in the unadjusted model $(\beta=1.37$ (95\% CI: $1.03,1.82), p=0.032$ ) and after adjustment for season of sampling $(p=0.017)$. For an increase of 3 -month mean residential $\mathrm{BC}$ concentrations with a factor 1.76 $\left(0.84 \mu \mathrm{g} / \mathrm{m}^{3}\right.$ (p25) to $1.48 \mu \mathrm{g} / \mathrm{m}^{3}$ (p75)), an increase of 3rd trimester HCC with a factor 1.54 (95\% CI: 1.08, 2.18) was estimated in the model, adjusted for season of sampling. The model including season of sampling and residential 3-month mean $\mathrm{NO}_{2}$ concentrations explained $7.7 \%$ of the variation in $3 \mathrm{rd}$ trimester $\mathrm{HCC}$, season of sampling and 3-month mean $\mathrm{BC}$ concentrations explained $5.9 \%$ of the variation in 3rd trimester HCC.

Residential distance to a major road was negatively associated with second trimester HCC in the unadjusted model ( $\beta=0.82$ (95\% CI: $0.70,0.96), p=0.016)$ and in the season-adjusted model $(p=0.011)$. For an increase in distance to major roads with a factor $4.49(143 \mathrm{~m}$ (p25) to $642 \mathrm{~m}$ (p75)), a decrease of 2nd trimester HCC with a factor 0.82 (95\% CI: 0.70, 0.95) was estimated in the model, adjusted for season of sampling. This model explained $7.8 \%$ of the variation in 2 nd trimester HCC. Distance to major roads was also negatively associated with 3rd trimester $\mathrm{HCC}$ in the unadjusted model ( $p=$ $0.040)$, for an increase of distance to a major road with a factor 5.25 (114 m (p25) to $598 \mathrm{~m}(\mathrm{p} 75))$, a decrease of

Table 4 Spearman rank correlations between residential exposure in the 3rd trimester study population $(\mathrm{n}=81)$

\begin{tabular}{|c|c|c|c|c|c|c|c|}
\hline & BC & $\mathrm{NO}_{2}$ & Distance to major road & Small greenspace & Large greenspace & Noise & ADI \\
\hline \multirow[t]{7}{*}{$\overline{P M} 2.5$} & $0.61^{*}$ & $0.55^{*}$ & -0.06 & $-0.19^{*}$ & $-0.31^{*}$ & 0.01 & 0.04 \\
\hline & $B C$ & $0.89^{*}$ & $-0.24^{*}$ & $-0.22^{*}$ & $-0.30^{*}$ & 0.18 & $0.31^{*}$ \\
\hline & & $\mathrm{NO}_{2}$ & $-0.32^{*}$ & $-0.21^{*}$ & $-0.28^{*}$ & $0.24^{*}$ & $0.39^{*}$ \\
\hline & & & Distance to major road & 0.13 & $0.26^{*}$ & $-0.31^{*}$ & -0.25 \\
\hline & & & & Small greenspace & $0.41^{*}$ & $-0.37^{*}$ & -0.08 \\
\hline & & & & & Large greenspace & $-0.15^{*}$ & -0.19 \\
\hline & & & & & & Noise & $0.25^{*}$ \\
\hline
\end{tabular}

${ }^{*}$ Significant correlations $(p<0.05)$

Note: Air pollutants were modelled at the maternal home address, 3-month mean concentrations were calculated. Major roads include E- or N-roads. Access to small neighborhood greenspace is defined as access to $>0.2$ ha (ha) of greenspace within a travel distance of $400 \mathrm{~m}$ ( $\mathrm{m}$ ) from residence, access to large neighborhood greenspace is defined as access to $>10$ ha of greenspace within a travel distance of $800 \mathrm{~m}$ from residence. Noise exposure is evaluated as exposure above the WHO health-based guideline of $53 \mathrm{~dB}$ Lden (day-evening-night noise level). $A D I$ Area deprivation index, $\mathrm{NO}_{2} \mathrm{Nitrogen}$ dioxide, $P \mathrm{M}_{2.5}$ Fine particulate matter with an aerodynamic diameter $\leq 2.5 \mu \mathrm{m}, B C$ Black carbon 
Table 5 Associations between residential exposures and hair cortisol concentrations in the second and third pregnancy trimester

\begin{tabular}{|c|c|c|c|c|}
\hline & \multicolumn{2}{|l|}{ Model I } & \multicolumn{2}{|l|}{ Model II } \\
\hline & $p$-value & $\beta(95 \% \mathrm{Cl})$ & $p$-value & $\beta(95 \% \mathrm{Cl})$ \\
\hline \multicolumn{5}{|l|}{ Second trimester $(n=133)$} \\
\hline \multicolumn{5}{|l|}{ Exposure (p25-p75) } \\
\hline 3-month mean $\mathrm{PM}_{2.5}\left(9.66-13.64 \mu \mathrm{g} / \mathrm{m}^{3}\right)$ & 0.009 & $0.81(0.70,0.95)$ & 0.200 & $0.87(0.70,1.08)$ \\
\hline 3-month mean $\mathrm{NO}_{2}\left(18.37-30.22 \mu \mathrm{g} / \mathrm{m}^{3}\right)$ & 0.934 & $0.99(0.83,1.18)$ & 0.287 & $1.10(0.92,1.34)$ \\
\hline 3-month mean BC $\left(0.84-1.49 \mu \mathrm{g} / \mathrm{m}^{3}\right)$ & 0.551 & $0.94(0.79,1.13)$ & 0.775 & $1.03(0.84,1.27)$ \\
\hline Distance to major road (143-642 m) & 0.016 & $0.82(0.70,0.96)$ & 0.011 & $0.82(0.70,0.95)$ \\
\hline Access to a small NHGS & 0.117 & $0.68(0.42,1.10)$ & 0.061 & $0.63(0.38,1.02)$ \\
\hline Access to a large NHGS & 0.073 & $0.77(0.57,1.03)$ & 0.095 & $0.78(0.59,1.04)$ \\
\hline \multicolumn{5}{|l|}{ Third trimester $(n=81)$} \\
\hline \multicolumn{5}{|l|}{ Exposure (p25-p75) } \\
\hline 3-month mean $\mathrm{PM}_{2.5}\left(9.59-13.27 \mu \mathrm{g} / \mathrm{m}^{3}\right)$ & $0.227^{*}$ & $1.20(0.89,1.62)$ & $0.051^{*}$ & $1.46(1.01,2.11)$ \\
\hline 3-month mean $\mathrm{NO}_{2}\left(18.35-30.00 \mu \mathrm{g} / \mathrm{m}^{3}\right)$ & $0.016^{*}$ & $1.42(1.07,1.88)$ & $0.008^{*}$ & $1.53(1.12,2.09)$ \\
\hline 3-month mean BC $\left(0.84-1.48 \mu \mathrm{g} / \mathrm{m}^{3}\right)$ & $0.032^{*}$ & $1.37(1.03,1.82)$ & $0.017^{*}$ & $1.54(1.08,2.18)$ \\
\hline Distance to major road (114-598 m) & 0.040 & $0.74(0.55,0.99)$ & 0.055 & $0.75(0.56,1.01)$ \\
\hline Access to a small NHGS & 0.354 & $0.67(0.28,1.05)$ & 0.169 & $0.53(0.22,1.32)$ \\
\hline Access to a large NHGS & 0.062 & $0.65(0.41,1.02)$ & 0.019 & $0.57(0.36,0.91)$ \\
\hline
\end{tabular}

Note: Estimates ( $\beta$ ) of the linear regression models are presented with their $95 \%$ confidence intervals $(95 \% \mathrm{Cl})$ as a factor increase in hair cortisol concentrations for a factor increase in exposure from the 25th to the 75th percentile (p75/p25). Model I is unadjusted, Model II is adjusted for season of sampling, Significant associations $(p<0.05)$ are marked in bold. *Associations evaluated for 78 participants. Air pollutants were modelled at the maternal home address, 3-month mean concentrations were calculated. Major roads include E- or N-roads. Access to small neighborhood greenspace is defined as access to $>0.2 \mathrm{ha}$ (ha) of greenspace within a travel distance of $400 \mathrm{~m}(\mathrm{~m})$ from residence, access to large neighborhood greenspace is defined as access to $>10$ ha of greenspace within a travel distance of $800 \mathrm{~m}$ from residence. $\mathrm{Cl}$ Confidence interval, $\mathrm{NO}_{2}$ Nitrogen dioxide, $P M_{2.5}$ Fine particulate matter with an aerodynamic diameter $\leq 2.5 \mu \mathrm{m}, B C \mathrm{Black}$ carbon, NHGS Neighborhood greenspace. Significant associations $(p<0.05)$ are marked in bold

3rd trimester HCC with a factor 0.74 (95\% CI: 0.55, 0.99) was estimated. Distance to a major road explained $4 \%$ of the variation in 3rd trimester HCC. Adjusting the model for season of sampling slightly attenuated the association ( $\beta=0.75$ (95\% CI: 0.56, 1.01), $p=0.055$ ).

Access to a small neighborhood greenspace tended towards a significant negative association with 2 nd trimester HCC ( $\beta=0.68$ (95\%CI: $0.42,1.10), p=0.117$ for the unadjusted model and $\beta=0.63$ (95\% CI: $0.38,1.02, p=$ 0.061 for the season-adjusted model) and was not significantly associated with 3rd trimester $\mathrm{HCC}$ before or after adjustment for season of sampling $(\beta=0.67$ (95\%CI: $0.28,1.05$ ), $p=0.354$ and $\beta=0.53$ (95\%CI: 0.22 , 1.32), $p=0.169$ resp.). Access to a large neighborhood greenspace tended towards a significant negative association with 2nd trimester HCC ( $\beta=0.77$ (95\% CI: 0.57, 1.03), $p=0.073$ for the unadjusted model, and $\beta=0.78$ (95\% CI: $0.59,1.04), p=0.095$ for the season-adjusted model). Access to a large neighborhood greenspace also tended towards a significant negative association with 3rd trimester HCC in the unadjusted model $(\beta=0.65$ (95\% CI: 0.41, 1.02, $p=0.062$ ), we observed a significant negative association after adjustment for season of sampling ( $\beta=0.57$ (0.36, 0.91), $p=0.019$ ).

We tested whether access to a neighborhood greenspace moderated the associations between air pollution exposure, proximity to major roads and maternal biological stress. We found no significant interaction between access to a small or large neighborhood greenspace and air pollution constituents in relation to 2nd or 3rd trimester HCC (see Table S2 for details). We did observe a significant interaction between access to a large neighborhood greenspace (NHGS) and distance to major roads in relation to 2 nd trimester HCC in both the unadjusted model, as presented in Fig. 1, and in the model adjusted for season of sampling ( $p$-interaction $=$ 0.021, p-interaction $=0.034$ resp.). Distance to major roads was significantly associated with 2nd trimester HCC for participants without access to a large NHGS ( $\beta$ $=0.64(95 \%$ CI: $0.48,0.85) p=0.003)$. The association was not significant for participants with access to a large NHGS ( $\beta=0.92$ (95\% CI: 0.77, 1.11), $p=0.399$ ). The season-adjusted interaction model explained $10.8 \%$ of the variations in 2nd trimester HCC.

The interaction between access to a large neighborhood greenspace (NHGS) and distance to major roads in relation to 3rd trimester HCC tended towards significance in the unadjusted model (p-interaction $=0.073$ ), as presented in Fig. 2, and after adjustment for season of sampling $(p$-interaction $=0.080)$. For pregnant women without access to a large NHGS, we found a significant association between distance to major roads and 3rd 


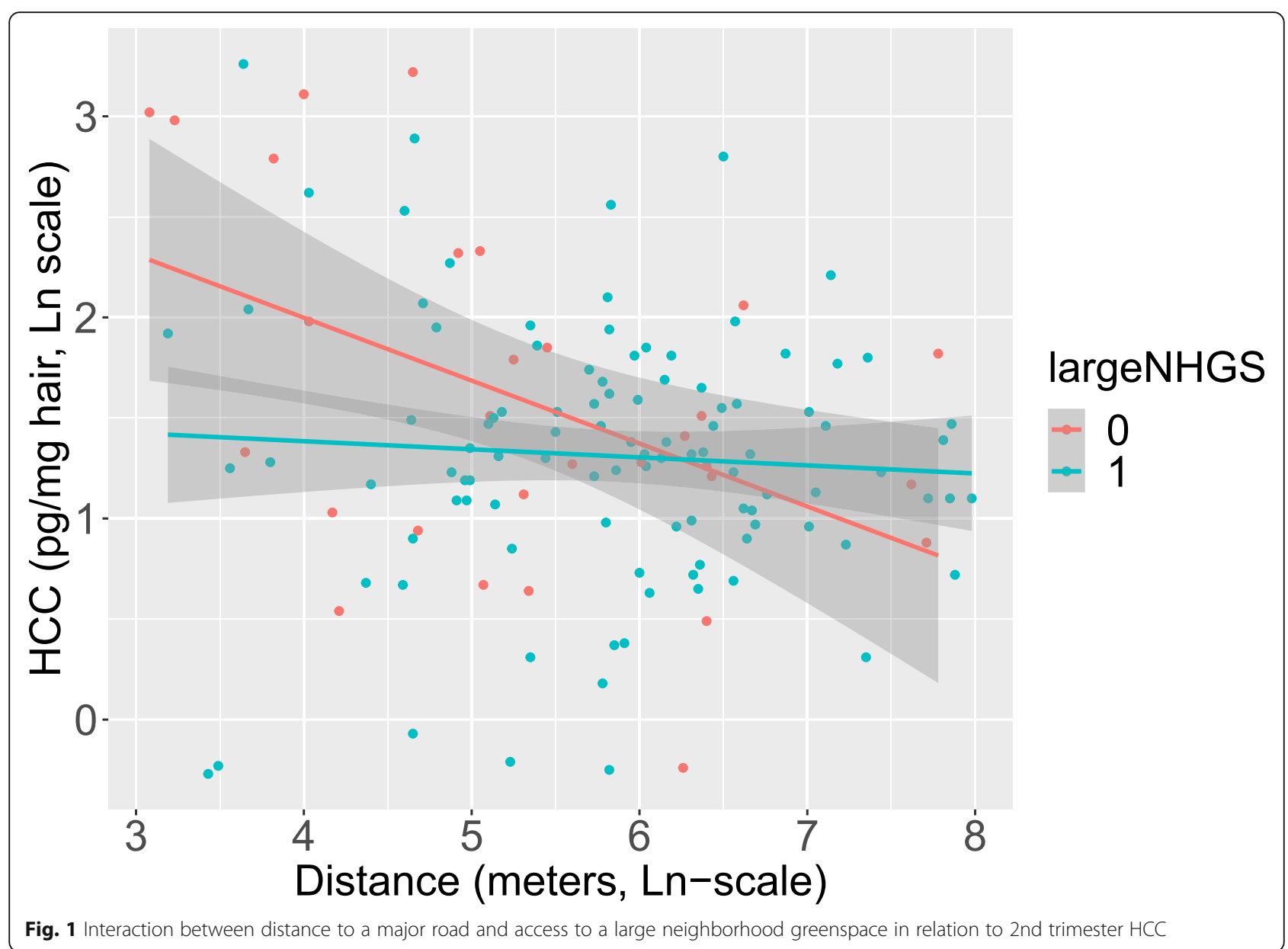

trimester HCC ( $\beta=0.53$ (95\% CI: $0.30,0.94), p=0.030)$ after adjustment for season of sampling. The association was not significant for pregnant women with access to a large NHGS ( $\beta=0.96$ (95\% CI: 0.68, 1.36), $p=0.816$ ). The interaction model, adjusted for season of sampling, explained 9.6\% of the variations in 3rd trimester HCC.

In a sensitivity analysis, we evaluated the significance of associations between 1-year mean $\mathrm{PM}_{2.5}, \mathrm{NO}_{2}$ and $\mathrm{BC}$ concentrations and HCC to reflect the participants' longer-term residential exposure to air pollution. Results are presented in Table S3. Extending the exposure period did not change our results much, we found significant positive associations between 1-year mean $\mathrm{NO}_{2}$ concentrations and 3rd trimester HCC in the unadjusted model and in the model, adjusted for season of sampling ( $\beta=1.49$ (95\% CI: $1.09,2.04), p=0.013$ and $\beta=1.44$ (95\% CI: 1.05, 1.99), $p=0.024$, resp.) and between 1-year mean $\mathrm{BC}$ concentrations and 3rd trimester HCC $(\beta=$ 1.39 (95\% CI: 1.01, 1.93), $p=0.046$ ). After adjustment for season of sampling, the association between 1-year mean BC concentrations and 3rd trimester HCC slightly attenuated ( $p=0.083, \beta=1.36$ (95\% CI: 0.96, 1.92). The robustness of our results was also evaluated by additional adjustment of our models with daily hair washing. Our results, presented in Table S4, remained robust. Additional adjustment of the models for maternal age, pre-pregnancy BMI, educational attainment and ADI slightly strengthened the estimated associations of distance to major roads with 2nd and 3rd trimester $\mathrm{HCC}$ and of residential exposure to $\mathrm{NO}_{2}, \mathrm{BC}$ and access to large NHGS with 3rd trimester HCC (see Table S5 for details). Excluding participants of non-European origin did not change the statistical significance of the results (see Table S6 for details).

\section{Discussion}

This study provides new insights in the relation between residential exposure to air pollution, road traffic, residential access to neighborhood greenspaces and hair cortisol as a biomarker for longer-term biological stress during pregnancy. We observed significant positive associations between residential 3-month mean $\mathrm{NO}_{2}$ and $\mathrm{BC}$ concentrations and maternal biological stress in the 3rd pregnancy trimester. It should be noted that $\mathrm{NO}_{2}$ exposure levels were strongly correlated with $\mathrm{BC}$ exposure levels $(r=0.89)$, making it impossible to disentangle the 


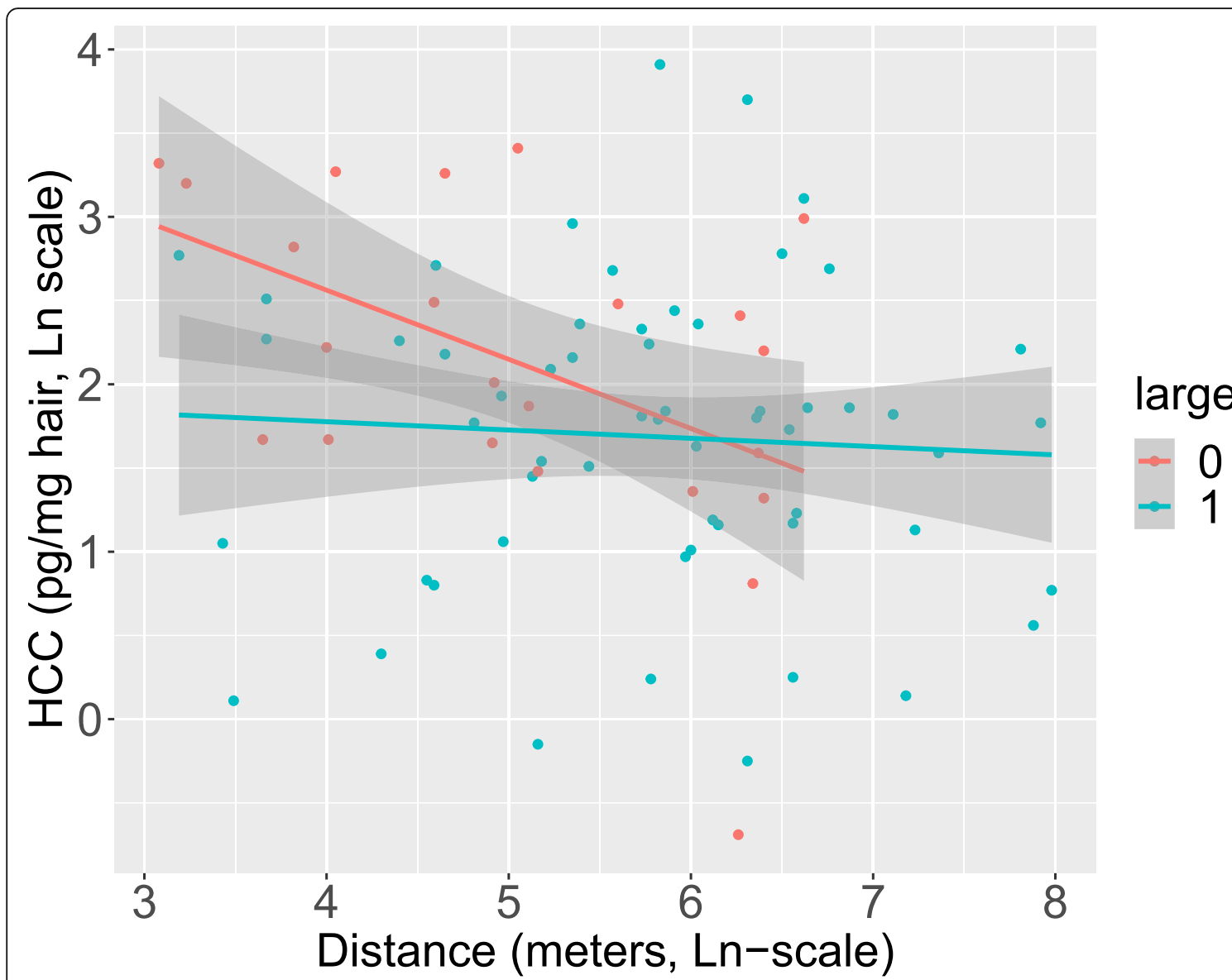

Fig. 2 Interaction between distance to a major road and access to a large neighborhood greenspace in relation to 3rd trimester HCC

effects of both pollutants. In urban settings, road traffic is the principal source of $\mathrm{NO}_{2}$ and $\mathrm{BC}$ in ambient air [60]. We also observed a significant association between residential proximity to major roads and maternal biological stress in the 3rd pregnancy trimester in the unadjusted model, the significance slightly attenuated after adjustment of the model for season of sampling. As previously reported, residential proximity to major roads and maternal biological stress in the 2nd pregnancy trimester were significantly associated [61]. We observed a significant negative association between 3-month mean $\mathrm{PM}_{2.5}$ concentrations and 2nd trimester $\mathrm{HCC}$ in the unadjusted analysis, the association did not remain significant after adjustment for season of sampling, indicating that the unadjusted analysis may have been confounded by seasonal variations in $\mathrm{PM}_{2.5}$ concentrations. The difference in significant associations between traffic-related exposures and 2nd and 3rd trimester HCC may be due to the difference in study population between both trimesters or to the increase in circulating cortisol concentrations towards the end of pregnancy, which is a normal biological process [24]. Our observations are in line with recent human studies that reported associations between air pollutants and short-term variations in cortisol secretion. In a panel study among 43 students in Shanghai, residential exposure to $\mathrm{PM}_{2.5}$ was associated with higher serum cortisol levels [13]. In a cross-sectional analysis of 1793 adults, residential $\mathrm{NO}_{2}$ exposure was associated with higher wake-up salivary cortisol [14]. To our knowledge, only one epidemiological study has examined the association between personal air pollution exposure and HCC; the study, including Belgian schoolchildren and adolescents, did not find a significant relationship [62]. Pregnancy however, is a vulnerable period for both mother and fetus [63]. Several mechanisms potentially underlie the association between air pollution and biological stress during pregnancy. Air pollutants may induce oxidative stress and low grade inflammation [64]. Depending on size and chemical composition, inhaled air pollution constituents may translocate from the lungs to the systemic circulation or migrate via olfactory transport to the brain and directly interact with brain tissues including the hypothalamus [11]. During pregnancy, oxidative stress is known to be higher than in the non-pregnant state; residential exposure to air pollutants and road traffic may 
further amplify the level of maternal oxidative stress [65]. Oxidative stress may in turn lead to low grade inflammation and HPA axis activation, resulting in a marked increase in the secretion of cortisol into the circulation [66]. In addition to indirect activation of the HPA axis by systemic low grade inflammation, low grade inflammation in the brain may directly activate the hypothalamus [67]. Flanders, the IPANEMA study region, is characterized by a dense road network and high emissions from traffic [68]. The fraction of the Flemish population, living and working in close proximity to traffic, is high and access to neighborhood greenspace is typically limited. Interestingly, in our urban and suburban pregnancy cohort, we observed a significant negative association of access to a large neighborhood greenspace of more than 10 ha within $800 \mathrm{~m}$ travel distance from residence, e.g. an urban park, with 3rd trimester HCC. Moreover, access to a large neighborhood greenspace significantly moderated the association between residential proximity to major roads and maternal biological stress in the 2nd pregnancy trimester. Beneficial relationships between residential access to greenspace and hair cortisol concentrations have been described in previous studies [28, 69]; whereas other studies have reported a beneficial impact of surrounding greenness on fetal growth and birth weight [70-73]. Neighborhood greenspace may improve health by relieving psychophysiological stress, supporting physical activity, increasing social contacts and by reducing exposure to air pollution, noise and excessive heat [27, 74-76]. In our study, we found a weak inverse correlation between access to a large greenspace and residential air pollutant concentrations in the 3rd pregnancy trimester, but not in the 2nd trimester. This may suggest a moderating effect of residential access to a large greenspace, independent of the effect on air pollution exposure levels.

The added value of prospective cohort studies such as IPANEMA, is the possibility to provide more insight into early pathophysiological mechanisms, triggered by air pollution exposure, in real-world settings. The urban and suburban character of the IPANEMA cohort made it possible to go deeper into traffic-related air pollution exposure, notwithstanding the low number of participants. Residential exposure to air pollution was estimated using a high spatial resolution model, residential mobility of participants was considered. In addition to maternal traffic and air pollution exposure, we took access to neighborhood greenspaces into account. Evaluation of only one residential environmental exposure i.e. air pollution, ignoring potential interaction with other jointly occurring exposures i.e. access to greenspaces, could lead to an inaccurate estimate of the true effect of exposures [77]. We measured hair cortisol concentrations, a novel method in epidemiological studies to retrospectively determine longer-term biological stress in a non-invasive and reliable way. Hair samples were collected according to a strict protocol by trained midwives at the in-hospital consultation to avoid interindividual differences in hair collection. Some limitations of the study need to be addressed. In this study, we had a limited number of participants and did not have the same study population in the second and third pregnancy trimester, leading to differences in residential exposures. We had a considerable percentage of missing questionnaire-based data. Future prospective cohort studies, ideally including a larger number of participants from pre-conception onwards, should enhance efforts to collect questionnaires from all participants, including relevant information on time spent in residential neighborhood greenspaces, physical activity, wellbeing and health. We also recommend future studies to take the different vegetation structures of greenspaces into account and assess qualitative characteristics of greenspaces, such as amenities, aesthetics, walkability and safety. Another limitation of our study is that we assessed air pollutant concentrations by estimation, not by measurement. The exposure assessment was also limited to residential surroundings, we did not consider air pollution exposure while commuting and working. Future studies may consider additional assessment of personal air pollution exposure using portable environmental sensors [78]. IPANEMA participants were mostly of a higher socioeconomic status, it was therefore not possible to explore increased vulnerability to environmental exposure in participants with lower SES. Moreover, the neighborhood SES indicator in this study did not reflect participants with lower socio-economic status. In literature, the pattern of air pollution is often described as Ushaped, although the most deprived areas have the highest levels of poor air quality, the least deprived areas also experience higher levels of air pollutants than some other social groups [50]. In our cohort, the mean ADI was $18.1 \%$ for lower educated mothers, $15.3 \%$ for medium education mothers and, as described in literature, we observed a slightly higher ADI of $15.6 \%$ for higher educated women. Future studies should enhance efforts to include participants of all SES.

\section{Conclusions}

This study observed significant positive associations between residential exposure to traffic-related air pollution during pregnancy and longer-term biological stress in the 2 nd and 3rd trimester of pregnancy. In the 2nd trimester of pregnancy, the association was significantly moderated by residential access to a large neighborhood greenspace. Air pollution and urban spatial planning are in the center of public debate in Flanders. Because of the ubiquitous nature of traffic-related air pollution and the adverse pregnancy outcomes that have been associated 
with elevated maternal biological stress for both mothers and babies, even a small increase in maternal biological stress may be of public health interest. Our research, if confirmed in future studies, may provide guidance towards a more sustainable urban planning and support environmental health protection for both pregnant women and their babies.

\section{Supplementary Information}

The online version contains supplementary material available at https://doi. org/10.1186/s12940-021-00697-z.

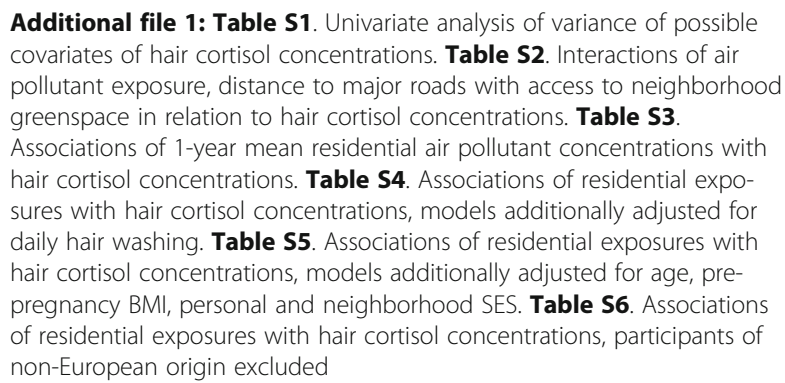

\section{Abbreviations}

ADI: Area deprivation index; BC: Black carbon; BMI: Body mass index; HCC: Hair cortisol concentrations; HPA axis: Hypothalamic-pituitary-adrenal; HPLC: High-Performance Liquid Chromatography; IPANEMA: Impact of Particulate Matter on Mothers and Babies in Antwerp; IRCEL: Belgian Interregional Environment Agency; LC-MS/MS: Liquid chromatography and tandem mass spectrometry; Lden: Day-evening-night noise level; LOQ: Limit of quantification; NHGS: Neighborhood greenspace; $\mathrm{NO}_{2}$ : Nitrogen dioxide; $\mathrm{PM}_{2.5}$ : Particulate matter with an aerodynamic diameter $\leq 2.5 \mu \mathrm{m}$; RIOIFDM: Air quality interpolation model combined with Immission Frequency Distribution Model; SES: Socioeconomic status; WHO: World Health Organization

\section{Acknowledgements}

The authors wish to thank the IPANEMA study participants and the nurses and obstetricians at the Antwerp University Hospital that recruited the participants. Exposure data was provided by the Flemish Department of Environment and Spatial Development, the Flemish Institute for Technological Research, the Belgian Interregional Environment Agency and the Belgian Royal Meteorological Institute (KMI). Erik Fransen (Antwerp University Doctoral School) provided relevant insights in statistical data-analysis.

\section{Authors' contributions}

VJV contributed to the study design, data acquisition, analysis and interpretation and was the first author of the manuscript draft. SR contributed to data interpretation, data visualization and revision of the manuscript. NL contributed to the study concept and design and revision of the manuscript. EG and AC contributed to the data analysis and revision of the manuscript. LP, EV, WL and CV contributed to the acquisition of environmental data. PM contributed to the environmental data analysis. FN conducted the analysis of hair cortisol and therefore contributed to the biomarker data acquisition. LVdE contributed to the in-hospital data acquisition. YJ supervised the IPANEMA study and contributed to the study concept and acquisition of data. GS contributed to the study concept, study design and revision of the manuscript and provided general guidance. The authors read and approved the final manuscript.

\section{Funding}

Veerle Verheyen was supported by a VITO PhD scholarship. The IPANEMA study was sponsored by the Antwerp University. This research did not receive a specific grant from funding agencies in the public, commercial or not-for-profit sectors.

\section{Availability of data and materials}

The datasets used and analyzed during the current study are available from the corresponding author on reasonable request.

\section{Ethics approval and consent to participate}

The study protocol was approved by the ethical committee of the University of Antwerp (14/40/411). All participants gave written informed consent. All co-authors have read the manuscript and consented with publication.

\section{Consent for publication}

Not applicable.

\section{Competing interests}

The authors declare that they have no competing interests.

\section{Author details}

${ }^{1}$ Flemish Institute for Technological Research (VITO), Mol, Belgium. ${ }^{2}$ Department of Biomedical Sciences, University of Antwerp, Antwerp, Belgium. ${ }^{3}$ Belgian Interregional Environment Agency, Brussels, Belgium. ${ }^{4}$ The Department of Public Health, University of Southern Denmark, Odense, Denmark. ${ }^{5}$ Department of Obstetrics and Gynecology, Antwerp University Hospital, Antwerp, Belgium. ${ }^{6}$ People and Health, Thomas More University College, Lier, Belgium. ${ }^{7}$ Global Health Institute, Faculty of Medicine, University of Antwerp, Antwerp, Belgium. ${ }^{8}$ Antwerp Surgical Training, Anatomy and Research Centre, University of Antwerp, Antwerp, Belgium.

Received: 3 June 2020 Accepted: 1 February 2021 Published online: 11 February 2021

\section{References}

1. Kingsley SL, Eliot MN, Whitsel EA, Huang YT, Kelsey KT, Marsit CJ, et al. Maternal residential proximity to major roadways, birth weight, and placental DNA methylation. Environ Int. 2016;92-93:43-9.

2. Dadvand P, Ostro B, Figueras F, Foraster M, Basagaña X, Valentín A, et al. Residential proximity to major roads and term low birth weight: the roles of air pollution, heat, noise, and road-adjacent trees. Epidemiology. 2014;25: 518-25.

3. Zhu X, Liu Y, Chen Y, Yao C, Che Z, Cao J. Maternal exposure to fine particulate matter (PM2.5) and pregnancy outcomes: a meta-analysis. Environ Sci Pollut Res. 2015;22:3383-96.

4. Barker DJP, Godfrey KM, Gluckman PD, Harding JE, Owens JA, Robinson JS. Fetal nutrition and cardiovascular disease in adult life. Lancet. 1993;341:93841.

5. Barouki R, Melén E, Herceg Z, Beckers J, Chen J, Karagas M, et al. Epigenetics as a mechanism linking developmental exposures to long-term toxicity. Environ Int. 2018;114:77-86.

6. Pedersen M, Stayner L, Slama R, Sørensen M, Figueras F, Nieuwenhuijsen MJ, et al. Ambient air pollution and pregnancy-induced hypertensive disorders: a systematic review and meta-analysis. Hypertension. 2014;64: 494-500.

7. Pedersen M, Halldorsson TI, Olsen SF, Hjortebjerg D, Ketzel M, Grandström $C$, et al. Impact of road traffic pollution on pre-eclampsia and pregnancyinduced hypertensive disorders. Epidemiology. 2017;28:99-106.

8. Elshahidi $\mathrm{MH}$. Outdoor air pollution and gestational diabetes mellitus: a systematic review and meta-analysis. Iran J Public Health. 2019;48:9-19.

9. Abramson BL, Melvin RG. Cardiovascular risk in women: focus on hypertension. Can J Cardiol. 2014;30:553-9.

10. Dadvand P, Parker J, Bell ML, Bonzini M, Brauer M, Darrow LA, et al. Maternal exposure to particulate air pollution and term birth weight: a multi-country evaluation of effect and heterogeneity. Environ Health Perspect. 2013;121: 367-73.

11. Thomson EM. Air pollution, stress, and Allostatic load: linking systemic and central nervous system impacts. J Alzheimers Dis. 2019;69:597-614.

12. Thomson EM, Filiatreault A, Guénette J. Stress hormones as potential mediators of air pollutant effects on the brain: rapid induction of glucocorticoid-responsive genes. Environ Res. 2019;178:108717.

13. Niu Y, Chen R, Xia Y, Cai J, Ying Z, Lin Z, et al. Fine particulate matter constituents and stress hormones in the hypothalamus-pituitary-adrenal axis. Environ Int. 2018;119:186-92.

14. Hajat A, Hazlehurst MF, Golden SH, Merkin SS, Seeman T, Szpiro AA, et al. The cross-sectional and longitudinal association between air pollution and 
salivary cortisol: evidence from the multi-ethnic study of atherosclerosis. Environ Int. 2019:131:105062

15. Lee DY, Kim E, Choi MH. Technical and clinical aspects of cortisol as a biochemical marker of chronic stress. BMB Rep. 2015;48:209-16.

16. Stalder T, Kirschbaum C. Analysis of cortisol in hair - state of the art and future directions. Brain Behav Immun. 2012;26:1019-29.

17. Kirschbaum C, Tietze A, Skoluda N, Dettenborn L. Hair as a retrospective calendar of cortisol production-increased cortisol incorporation into hair in the third trimester of pregnancy. Psychoneuroendocrinology. 2009;34:32-7.

18. Stalder T, Steudte-Schmiedgen S, Alexander N, Klucken T, Vater A, Wichmann S, et al. Stress-related and basic determinants of hair cortisol in humans: a meta-analysis. Psychoneuroendocrinology. 2017;77:261-74.

19. Davenport MD, Tiefenbacher S, Lutz CK, Novak MA, Meyer JS. Analysis of endogenous cortisol concentrations in the hair of rhesus macaques. Gen Comp Endocrinol. 2006;147:255-61.

20. Heimbürge $S$, Kanitz $E$, Otten W. The use of hair cortisol for the assessment of stress in animals. Gen Comp Endocrinol. 2019;270:10-7.

21. Manenschijn L, Koper JW, Lamberts SWJ, Van Rossum EFC. Evaluation of a method to measure long term cortisol levels. Steroids. 2011;76:1032-6.

22. Cottrell EC, Seckl JR, Holmes MC, Wyrwoll CS. Foetal and placental 11BHSD2: a hub for developmental programming. Acta Physiol. 2014;210:28895.

23. Bärebring $L, O^{\prime}$ Connell $M$, Winkvist A, Johannsson $G$, Augustin $H$. Serum cortisol and vitamin D status are independently associated with blood pressure in pregnancy. J Steroid Biochem Mol Biol. 2019;189:259-64.

24. Hoffman MC, Mazzoni SE, Wagner BD, Laudenslager ML, Ross RG. Measures of maternal stress and mood in relation to preterm birth. Obstet Gynecol. 2016:127:545-52.

25. Banay RF, Bezold CP, James P, Hart JE, Laden F. Residential greenness: current perspectives on its impact on maternal health and pregnancy outcomes. Int J Womens Health. 2017;9:133-44.

26. Twohig-Bennett $\mathrm{C}$, Jones $\mathrm{A}$. The health benefits of the great outdoors: a systematic review and meta-analysis of greenspace exposure and health outcomes. Environ Res. 2018;166:628-37.

27. Markevych I, Schoierer J, Hartig T, Chudnovsky A, Hystad P, Dzhambov AM, et al. Exploring pathways linking greenspace to health: theoretical and methodological guidance. Environ Res. 2017;158:301-17.

28. Honold J, Lakes T, Beyer R, van der Meer E. Restoration in urban spaces. Environ Behav. 2016;48:796-825.

29. The Worldbank: Urban Development Overview. https:/wwww.worldbank.org/ en/topic/urbandevelopment/overview. Accessed 20 Nov 2020.

30. Bloemsma LD, Wijga AH, Klompmaker JO, Janssen NAH, Smit HA, Koppelman GH, et al. The associations of air pollution, traffic noise and green space with overweight throughout childhood: the PIAMA birth cohort study. Environ Res. 2019;169:348-56.

31. Kim S, Kim H, Lee JT. Interactions between ambient air particles and greenness on cause-specific mortality in seven Korean metropolitan cities, 2008-2016. Int J Environ Res Public Health. 2019;16:1866.

32. Van Den Eeden L, Lambrechts N, Verheyen V, Berth M, Schoeters G, Jacquemyn $Y$. Impact of particulate matter on mothers and babies in Antwerp (IPANEMA): a prospective cohort study on the impact of pollutants and particulate matter in pregnancy. BMJ Open. 2018;8:e020028.

33. Eurostat. Urban Europe statistics on cities, town and suburbs; 2016. https:// ec.europa.eu/eurostat/documents/3217494/7596823/KS-01-16-691-EN-N.pdf/ 0abf140c-ccc7-4a7f-b236-682effcde10f?t=1472645220000. Accessed 28 May 2020

34. Janssen S, Dumont G, Fierens F, Mensink C. Spatial interpolation of air pollution measurements using CORINE land cover data. Atmos Environ. 2008:42:4884-903.

35. Lefebvre W, Degrawe B, Beckx C, Vanhulsel M, Kochan B, Bellemans T, et al. Presentation and evaluation of an integrated model chain to respond to traffic- and health-related policy questions. Environ Model Software. 2013; 40:160-70.

36. Wilhelm M, Ritz B. Residential proximity to traffic and adverse birth outcomes in Los Angeles County, California, 1994-1996. Environ Health Perspect. 2003;111:207-16.

37. Poelmans L, Janssen L, Hambsch L. Landgebruik en ruimtebeslag in Vlaanderen, toestand 2016, uitgevoerd in opdracht van het Vlaams Planbureau voor Omgeving; 2019. https://www.milieuinfo.be/dms/d/d/ workspace/SpacesStore/56a309c7-504c-479e-853c-3e9d2d441425/la ndgebruik_ruimtebeslag_toestand2016.pdf. Accessed 6 Apr 2020
38. Verachtert E, Poelmans L, Vermeiren $K$, Hendrix R. Technische fiche groentypologieën Stadsmonitor. Studie uitgevoerd in opdracht van Agentschap Binnenlands Bestuur. 2018; https://gemeente-stadsmonitor.vlaa nderen.be/sites/gemeente-en-stadsmonitor/files/technische_fiche groentypes_stadsmonitor_jan2019.pdf. Accessed 6 Apr 2020.

39. Sauvé B, Koren G, Walsh G, Tokmakejian S, Van Uum SHM. Measurement of cortisol in human hair as a biomarker of systemic exposure. Clin Invest Med. 2007:30:E183-91.

40. Greff MJE, Levine JM, Abuzgaia AM, Elzagallaai AA, Rieder MJ, van Uum SHM. Hair cortisol analysis: an update on methodological considerations and clinical applications. Clin Biochem. 2019;63:1-9.

41. Abell JG, Stalder T, Ferrie JE, Shipley MJ, Kirschbaum C, Kivimäki M, et al. Assessing cortisol from hair samples in a large observational cohort: the Whitehall II study. Psychoneuroendocrinology. 2016;73:148-56.

42. Russell E, Kirschbaum C, Laudenslager ML, Stalder T, de Rijke Y, van Rossum EFC, et al. Toward standardization of hair cortisol measurement. Ther Drug Monit. 2015;37:71-5

43. Chen Z, Li J, Zhang J, Xing X, Gao W, Lu Z, et al. Simultaneous determination of hair cortisol, cortisone and DHEAS with liquid chromatography-electrospray ionization-tandem mass spectrometry in negative mode. J Chromatogr B Analyt Technol Biomed Life Sci. 2013;929:187-94.

44. Wester VL, Van Rossum EFC. Clinical applications of cortisol measurements in hair. Eur J Endocrinol. 2015;173:1-10.

45. Braig S, Grabher F, Ntomchukwu C, Reister F, Stalder T, Kirschbaum C, et al. Determinants of maternal hair cortisol concentrations at delivery reflecting the last trimester of pregnancy. Psychoneuroendocrinology. 2015;52:289-96.

46. Gray NA, Dhana A, Van Der Vyver L, Van Wyk J, Khumalo NP, Stein DJ. Determinants of hair cortisol concentration in children: a systematic review. Psychoneuroendocrinology. 2018;87:204-14.

47. Wester VL, Noppe G, Savas M, van den Akker ELT, de Rijke YB, van Rossum EFC. Hair analysis reveals subtle HPA axis suppression associated with use of local corticosteroids: the lifelines cohort study. Psychoneuroendocrinology. 2017;80:1-6.

48. Marteinsdottir I, Sydsjö G, Faresjö TE, Josefsson A. Parity-related variation in cortisol concentrations in hair during pregnancy. BJOG. 2020. https://doi. org/10.1111/1471-0528.16542.

49. Bleker LS, Roseboom TJ, Vrijkotte TG, Reynolds RM, de Rooij SR. Determinants of cortisol during pregnancy - the ABCD cohort. Psychoneuroendocrinology. 2017:83:172-81.

50. Fairburn J, Schüle SA, Dreger S, Hilz LK, Bolte G. Social inequalities in exposure to ambient air pollution: a systematic review in the WHO European region. Int J Environ Res Public Health. 2019;16(17):3127.

51. Schüle SA, Gabriel KMA, Bolte G. Relationship between neighbourhood socioeconomic position and neighbourhood public green space availability: an environmental inequality analysis in a large German city applying generalized linear models. Int J Hyg Environ Health. 2017;220:711-8.

52. Statistics Flanders. https://www.statistiekvlaanderen.be/kansarmoede-indexvan-kind-en-gezin. Accessed 15 Jan 2020.

53. Organisation for Economic Co-operation and Development (OECD): Country Note Early Childhood Education and Care Policy in the Flemish Community of Belgium (2000). http://www.oecd.org/belgium/earlychildhoodeducationa ndcare-reportsonbelgium.htm. Accessed 27 Jan 2020.

54. Moudon AV. Real noise from the urban environment. How ambient community noise affects health and what can be done about it. Am J Prev Med. 2009;37:167-71.

55. Eionet: Environmental Noise Directive (2016). https://cdr.eionet.europa.eu/ be/eu/noise/. Accessed 14 May 2020.

56. Miedema HME, Vos H. Noise annoyance from stationary sources: relationships with exposure metric day-evening-night level (DENL) and their confidence intervals. J Acoust Soc Am. 2004;116:334-43.

57. World Health Organization WHO. Environmental noise guidelines for the European region: World Health Organization; 2018. https://www.euro.who. int/_data/assets/pdf_file/0008/383921/noise-guidelines-eng.pdf. Accessed 3 May 2020

58. Weaver AM, Wellenius GA, Wu WC, Hickson DA, Kamalesh M, Wang Y. Residential distance to major roadways and cardiac structure in African Americans: cross-sectional results from the Jackson heart study. Environ Health. 2017:16(1):21.

59. Robinson O, Tamayo I, de Castro M, Valentin A, Giorgis-Allemand L, Krog $\mathrm{NH}$, et al. The urban exposome during pregnancy and its socioeconomic determinants. Environ Health Perspect. 2018;126(7):077005. 
60. Liu SV, Lin CF, Xue J. A meta-analysis of selected near-road air pollutants based on concentration decay rates. Heliyon. 2019;5(8)::02236.

61. Verheyen V, Van den Eeden L, Lambrechts N, Remy S, Govarts E, Nielsen F, et al. Residential proximity to major roads and neighbourhood green space in relation to biological stress in the second trimester of pregnancy in the IPANEMA cohort. Environ Epidemiol. 2019;3:411-2.

62. Van Aart CJC, Michels N, Sioen I, De Decker A, Bijnens EM, Janssen BG, et al. Residential landscape as a predictor of psychosocial stress in the life course from childhood to adolescence. Environ Int. 2018;120:456-63.

63. Makri A, Stilianakis NI. Vulnerability to air pollution health effects. Int J Hyg Environ Health. 2008;211:326-36.

64. Brook RD, Rajagopalan S, Pope CA, Brook JR, Bhatnagar A, Diez-Roux AV et al. Particulate matter air pollution and cardiovascular disease: an update to the scientific statement from the american heart association. Circulation. 2010:121:2331-78.

65. Miller MR, Shaw CA, Langrish JP. From particles to patients: oxidative stress and the cardiovascular effects of air pollution. Future Cardiol. 2012;8:577602.

66. John CD, Buckingham JC. Cytokines: regulation of the hypothalamopituitary-adrenocortical axis. Curr Opin Pharmacol. 2003;3(1):78-84.

67. Fuertes E, Standl M, Forns J, Berdel D, Garcia-Aymerich J, Markevych I, et al. Traffic-related air pollution and hyperactivity/inattention, dyslexia and dyscalculia in adolescents of the German GINIplus and LISAplus birth cohorts. Environ Int. 2016;97:85-92.

68. De Prins S, Dons E, Van Poppel M, Int Panis L, Van de Mieroop E, Nelen V, et al. Airway oxidative stress and inflammation markers in exhaled breath from children are linked with exposure to black carbon. Environ Int. 2014;73: 440-6.

69. Gidlow CJ, Randall J, Gillman J, Smith GR, Jones MV. Natural environments and chronic stress measured by hair cortisol. Landsc Urban Plan. 2016;148: $61-7$.

70. Ebisu K, Holford TR, Bell ML. Association between greenness, urbanicity, and birth weight. Sci Total Environ. 2016;542:750-6.

71. Dadvand P, Sunyer J, Basagaña X, Ballester F, Lertxundi A, FernándezSomoano $A$, et al. Surrounding greenness and pregnancy outcomes in four Spanish birth cohorts. Environ Health Perspect. 2012;120:1481-7.

72. Markevych I, Fuertes E, Tiesler CMT, Birk M, Bauer CP, Koletzko S, et al. Surrounding greenness and birth weight: results from the GINIplus and LISAplus birth cohorts in Munich. Health Place. 2014;26:39-46.

73. Nieuwenhuijsen MJ, Agier L, Basagaña X, Urquiza J, Tamayo-Uria I, GiorgisAllemand $\mathrm{L}$, et al. Influence of the urban exposome on birth weight. Environ Health Perspect. 2019;127(4):47007.

74. Dadvand P, de Nazelle A, Figueras F, Basagaña X, Su J, Amoly E, et al. Green space, health inequality and pregnancy. Environ Int. 2012;40:110-5.

75. Ward Thompson C, Roe J, Aspinall P, Mitchell R, Clow A, Miller D. More green space is linked to less stress in deprived communities: evidence from salivary cortisol patterns. Landsc Urban Plan. 2012;105:221-9.

76. Roe JJ, Aspinall PA, Thompson CW. Coping with stress in deprived urban neighborhoods: what is the role of green space according to life stage? Front Psychol. 2017:8:1760

77. Klompmaker JO, Janssen NAH, Bloemsma LD, Gehring U, Wijga AH, Brink C. Vanden, et al. associations of combined exposures to surrounding green, air pollution, and road traffic noise with cardiometabolic diseases. Environ Health Perspect. 2019;127(8):87003.

78. Liang L, Gong P, Cong N, Li Z, Zhao Y, Chen Y. Assessment of personal exposure to particulate air pollution: the first result of City health outlook (CHO) project. BMC Public Health. 2019;19(1):711.

\section{Publisher's Note}

Springer Nature remains neutral with regard to jurisdictional claims in published maps and institutional affiliations.

Ready to submit your research? Choose BMC and benefit from:

- fast, convenient online submission

- thorough peer review by experienced researchers in your field

- rapid publication on acceptance

- support for research data, including large and complex data types

- gold Open Access which fosters wider collaboration and increased citations

- maximum visibility for your research: over $100 \mathrm{M}$ website views per year

At $\mathrm{BMC}$, research is always in progress.

Learn more biomedcentral.com/submissions 